\section{The Influence of Posture on the}

\section{Effectiveness of Coughing}

\author{
CURRY, L. D. AND VAN EEDEN, C.*
}

*B.Sc. Physiotherapy IV, University of Siellenbosch.

\begin{abstract}
"Physiotherapy procedures. When one has a split sternum, can be excruciatingly painful. Knowing full well that the physiotherapy "as absolutely necessary (almost all patients have some basal atelectasis). that the procedure was scientific, and that it was for my benefit, and at all times co-operating to the utmost of my ability. I can recall the momentary resentment 1 experienced every time the physiotherapist entered the ward. How much more must this resentment build up in the untrained mind. which cannot appreciate the necessity for this retined, but vitally essential form of scientitic 'torture'."'
\end{abstract}

The importance of effective coughing for the removal of secretions, often a most painful procedure for the post-operative patient. is known to every physiotherapist. However, very little research has been done on this vilal aspect of chest physiotherapy.

\section{METHOD}

Twenty physiotherapy students served as subjects for the investigation of the effectiveness of coughing in ninc diflerent postures. They were examined by a physician and no clinical abnormalities were found ith respect to the respiratory and cardiovascular systems or the bony thorax. Furthermore lung function sifting tests were normal for all subjects.

The positions chosen represent a good cross section of those found in nursing and in physiotherapy treatment. The following postures were selected:

\section{Sidclving,}

2. Half-sidelying with both arms anterior.

3. Half-sidelying with the lower arm posterior.

4. Half-lying. legs extended.

5. Half-lying. legs flexed.

6. Supine, legs extended.

7. Supine, legs Hexed.

8. Long sitting and

9. Upright sitting over the side of the bed.

Cough measurements were taken from an Airflometer. These readings are influenced by the flow-rate of the exhaled air as well as by its volume. two important components of a cough. "The airflometer was held horizontally while the subject coughed into it ihrough a mouthpiece. A nose clip ensured no escape of air through the nasal passage. (Fig. I.)

The number of readings for a given subject in each of the positions varied from three to seven. Readings were only tabulated when the subject was familiar with the use of the Airflowmeter and ceased when readings reached a maximum plateau. The highest value oblained in each position was taken as the basis of comparison seeing that it was approximately the best of which the subject was capable.

\section{SUMMARY}

The infinence of different postures on the effectiveness of conghing was imvestigated. Twenty normal young "omen rerved as subjects and the averige airflow values were determined and standardized for each position. The host results were ohrainced in the upright position and this correlated perfectly with the anderlying physiology.

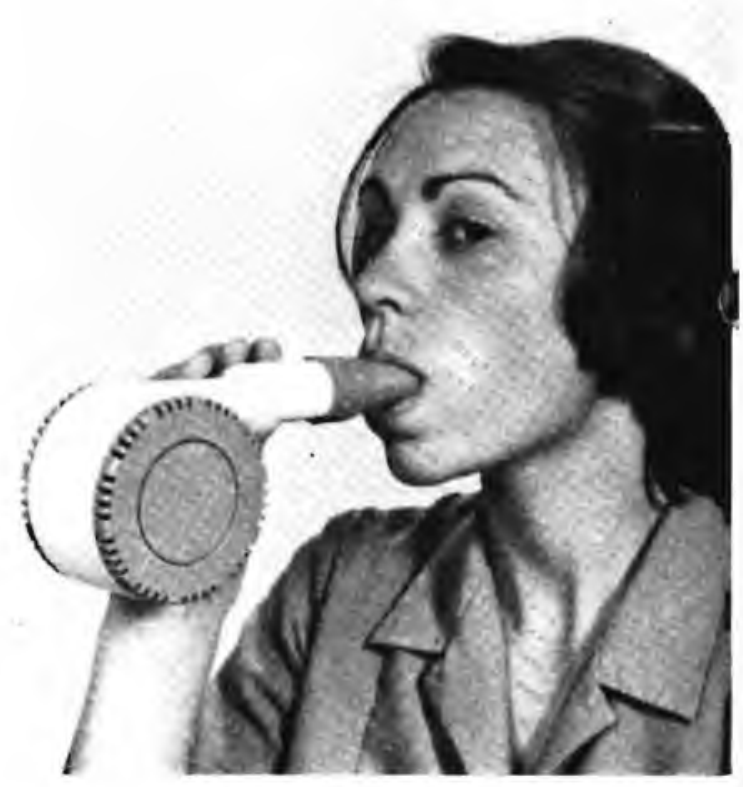

Fig 1: The Airflowmeter

\section{RESULTS}

The average airflow values and the standard deviation as well as the $95^{\prime \prime}$, confidence limits were calculated. The highest average airflow was obtained in upright sitting and the second highest in long sitting. The value obtained in upright sitting "as statistically significantly superior on a $1 "$ level.

The 20 subjects differed in vital capacity and therefo the airflow values were standardized with the uprigh position taken as $100^{\prime \prime}$.. (Fig. 2.)

Effectiveness of coughing increased with the change iı posture from side-lying to supine and from supine to a progressively more upright position. In both the supine and half-lying positions better results uere obtained with the legs flexed.

From the linear relation between the upright and long sitting positions (Fig. 3), it is apparent that subjects coughed consistently, i.e. subjects who coughed well rcgistered relatively higher readings in all the positions than those who coughed poorly.

From Fig. 2 we can see that the upright sitting position is the optimum posture for effective coughing.

\section{DISCUSSION}

The act of coughing can be analyzed into three phases:" (Fig. 4.) 


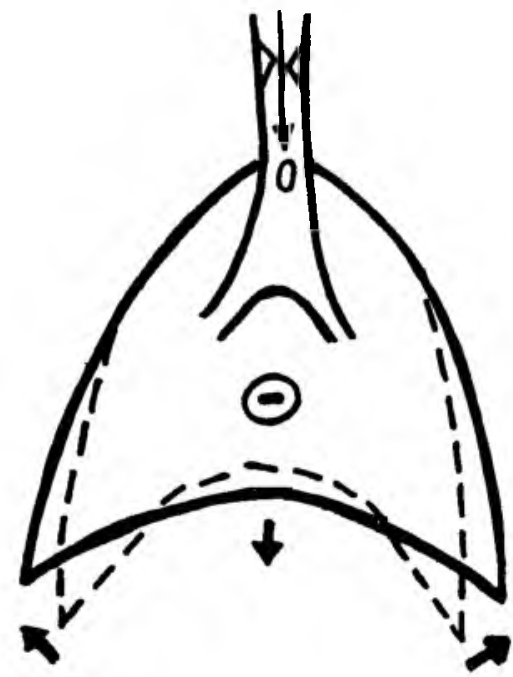

INSPIRATORY PHASE

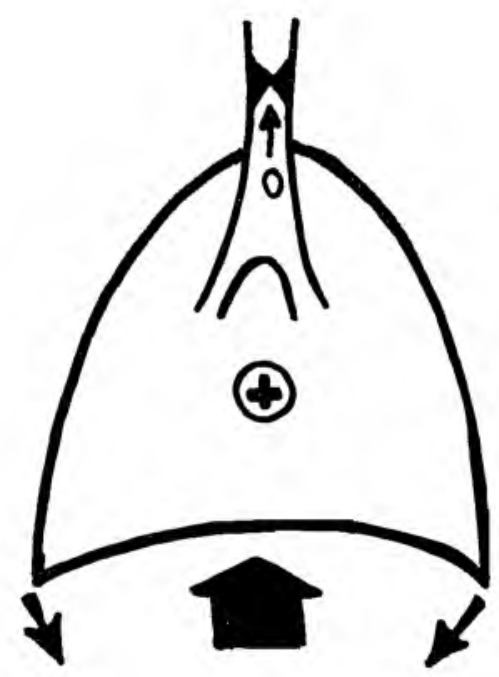

COMPRESSION PHASE

Fig. 4

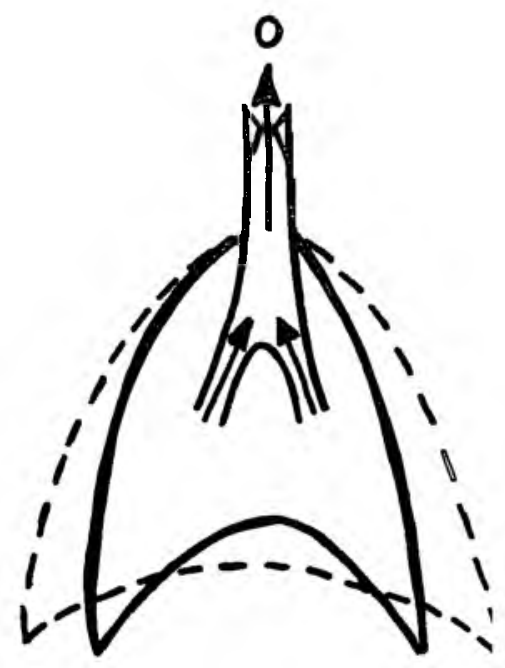

EXPULSION
PHASE
The inspiratory phase

A deep breath is taken moving into the lungs the bulk of the inspiratory reserve volume.

\section{The compression phase}

The glottis is quickly and tightly closed while the expiratory intercostal and the accessory muscles of respiration, especially the abdominal muscles, contract forcibly so that the intrathoracic and intra-abdominal pressures rise.

\section{The expulsion phase}

The glottis suddenly opens since the intra-abdominal pressure is now higher than the intrathoracic pressure and the diaphragm is pushed up, producing a violent, explosive movement of the air from the lower to the upper respiratory tract. The large pressure difference between alveolar pressure and upper tracheal pressure (now atmospheric) results in a very rapid flow rate.

In addition, the high intrathoracic pressure causes the non-cartilaginous part of the intrathoracic trachea to be compressed and inverted to $16 \%$ of its original size. The air rushing through this greatly narrowed trachea has a high linear velocity (calculated to be $85 \%$ of the speed of sound), ${ }^{4}$ and this dislodges foreign material or mucous secretions and pushes them into the pharynx from where they are expectorated.

The results obtained can be explained in terms of the following aspects of physiology:

The effectiveness of coughing is closely related to the functional residual capacity (FRC) at which it begins. (The FRC is the lung capacity which exists between the recoil of the lung which tends to collapse and the elastic forces of the thorax which tends to expand). The FRC decreases by $1000 \mathrm{ml}$ with the change from the upright to the supine position. ${ }^{5}$ This volume decrease is effected by the upward shifting of the diaphragm and the pressure of the abdominal contents as well as the increased size of the medial mediastinum as a result of the increased venous flow. ${ }^{6}$
A decreased FRC causes the elastic recoil of the lung to decrease, which in its turn causes a retarded peak expiratory flow. ${ }^{7}$ Thus the maximum peak expiratory flow (as found in a cough) will be decreased in a lying position and a less effective cough will be obtained.

Decreased FRC is also experienced after anaesthesia and is further decreased by the supine position assumed post-operatively. Further, with diffuse obstructive pulmonary airways syndrome (D.O.P.S.) where a situation of increased "trap gas" volume exists, supine postures lead to decreased FRC as well. ${ }^{B}$

We can conclude that posture and lung pathology should be carefully evaluated for maximum effectiveness of coughing.

\section{ACKNOWLEDGEMENTS}

Dr. J. C. Vermaak, M.B., Ch.B., M.Med. (Anaes.) Dr. J. B. de Vaal, M.B., Ch.B., M.Med. (Int.) of thd Respiratory Unit, the personnel of the Lung function laboratories, Tygerberg Hospital, and Prof. P. A. Foster, M.B. Ch.B., F.F.A., R.C.S.I., D.A. (Dublin), D.A. (Lond.), Head, Department of Anaesthetics, University of Stellenbosch and Tygerberg Hospital, Tiervlei, for their encouragement and help.

\section{REFERENCES}

1. Schamroth, L. (1976): Personal experiences, S. Afr. Med. J., 50, 297.

2. Friedman, M. (1975): Assessment of Lung Function using an Airflowmeter, Lancet, 1, 7902.

3. Kapandji, I. A. (1970): The Physiology of the Joints, 2nd ed., Edinburgh, Churchill Livingstone, 3, 164.

4. Comroe, J. H. (1965): Physiology of Respiration, 2nd ed., Chicago, Year Book Medical Publishers Incorporated, p. 122.

5. Nunn, J. F. (1969): Applied Respiratory Physiology, Great Britain, Butterworth \& Co. (Publishers) Ltd., p. 90.

6. Hewlett, A. M., Hulands, G. H., Nunn, J. F., Heath, J. R. (1974): Functional Residual Capacity during Anaesthesia, Brit. J. of Anaesthesia, 46, 7, $479-485$. 